Research Paper:

\title{
ADKAR Model and Nurses' Readiness for Change
}

\author{
Alice Kachian $^{1}$ 이, Sona Elyasi ${ }^{* *}$,
}

1. Department of Medical Surgical Nursing, School of Nursing \& Midwifery, Iran University of Medical sciences, Tehran, Iran. 2. Department of Biostatistics, School of Public Health, Iran University of Medical Sciences, Tehran, Iran.

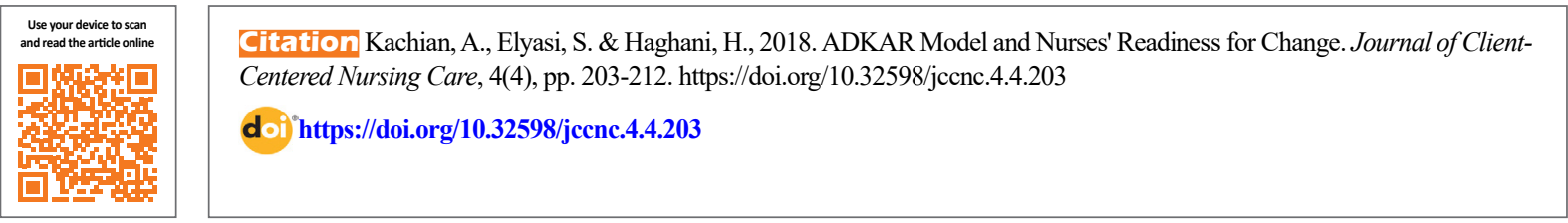

\section{(1) (9)}

Article info:

Received: 23 May 2018

Accepted: 27 Aug 2018

Published: 01 Nov 2018
Keywords:

Change management, ADKAR model, Readiness for change, Nursing process

\section{A B S T RA C T}

Background: Transformation is the greatest problem that all organizations face today. By the participation of people in the change projects, the possible resistance rate is reduced and the process of change is accelerated. The readiness of individuals makes them more involved in the change process. The current study aimed at investigating the readiness of using nursing Kardex through applying ADKAR Model by nurses working in hospitals affiliated to Iran University of Medical Sciences.

Methods: current descriptive, cross sectional study was conducted on 320 nurses working in hospitals in Tehran, Iran. The subjects in each hospital were selected proportional to the size of the population, using convenient sampling method. Data were collected by demographic and ADKAR model questionnaires and analyzed by descriptive statistics with SPSS V. 16.

Results: Most of the subjects ( $95 \%$ ) were female. The mean age of the subjects was 31.86 years with a mean working experience of 8.21 years. Moreover, $90 \%$ of the samples hold a bachelor's degree and most of them served as an official employee; $67.2 \%$ of nurses worked in university teaching hospitals and $32.8 \%$ in general hospitals. The results showed relative readiness of the nurses (more than half of the subjects got average score above 3 in all components) and the efficiency of the ADKAR model to assess their readiness.

Conclusion: According to the results, it is recommended to increase the knowledge and ability of nurses to employ nursing Kardex, strengthen supportive factors, especially in non-educational hospitals, to make the changes, and increase the participation of nurses.

\footnotetext{
* Corresponding Author:

Sona Elyasi, MSc.

Address: Department of Medical Surgical Nursing, School of Nursing \& Midwifery, Iran University of Medical sciences, Tehran, Iran.

Tel: +98 (919) 4829396

E-mail: selyasi1989@gmail.com
} 


\section{Highlights}

- Transformation and change are one of the greatest challenges of any organizations.

- Participation of the staff in the change reduces the possible resistance and accelerates the process of change.

- The readiness of individuals makes them more involved in the change process.

- We aimed to evaluate the readiness of Iranian nurses in using Nursing Kardex, by using the ADKAR Model.

- The results showed relative readiness of the nurses and the efficiency of the ADKAR model to assess their readiness.

\section{Plain Language Summary}

Today, transformation and change is the greatest challenge of all organizations. By participation of staff in the change process, the possible resistance is reduced, and the process of change is accelerated. The readiness of individuals makes them more involved in the change process. We tried to evaluate the preparedness of nurses to use Nursing Kardex by applying the ADKAR Model for change. The study samples were nurses working in educational hospitals in Tehran City, Iran. The results showed relative readiness of the nurses and the efficiency of the ADKAR model to assess their readiness. Thus, we suggest that the nurses should be encouraged to employ Nursing Kardex be increased, especially in non-educational hospitals to increase the participation of nurses.

\section{Background}

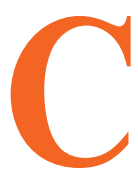

hange, development, maturity, and improvement are the most outstanding characteristics of organizations and institutions in today's competitive mode aiming to improve the quality of people's lives (Bakhshi 2011). Today, the greatest problem that any organization faces with is the concept of "change" (Carnall 2002). The Oxford Dictionary defines "change" as "being different" or "to make difference". Change is a dynamic process and not a one-time event (Oxford 2018).

It is difficult to understand and control dynamic phenomena. Dynamic phenomena arise from the interaction of various factors. Changes in organizations and societies are associated with collective and group work. It is not easy to bring people together collectively to work hard and dearly pursue the goals and willing of the group. In many cases, people do not accompany with change and resist it (Senge 2006).

Constant and continuous adaptation of companies with rapid changes in the market is a prerequisite for survival and growth. Changes lead to increased stress; however, when it comes to understanding the necessity and benefits of change, it leads to increased productivity. Good relationship between leadership and employees leads to significant benefits and a sense of security. When it is asked to be changed, it has a negative effect on productivity and causes job dissatisfaction (Halkos 2012).

In many countries, in recent decades, using Nursing Process in taking care of the patients has attracted the researchers' attention, and results of many studies suggest improvements of quality of taking care through using nursing process (Hagos et al. 2014). Studies show that the employment of nursing process led to optimum results in Iran (Farahani et al. 2016).

After several studies in recent years, following the favorable outcomes of this change in the nursing, experts came to the conclusion that the nursing process can be directly used to take care of patients. In this regard, the Nursing Deputy of Iran University of Medical Sciences decided to add nursing diagnosis to nursing Kardex. According to the sources of hospital accreditation, as well as the nursing process, including nursing diagnosis, planning, implementation, and assessment, it is necessary to record these steps to continue providing care according to the accreditation standards. On the other hand, in addition to their medical diagnosis, patients have other needs presented in the form of nursing diagnosis. Currently, nurses carry out care routinely based on the process, which does not involve the accurate recording of the steps in the Kardex or patient records (Matbouei, Mohammadi \& Zargarzadeh 2015). 
Given the importance of care based on nursing process, before the implementation of this plan, it is necessary to assess nurses' readiness to implement this plan in order to prevent potential resistance. Hospital nursing managers report that their main problem in dealing with changes is the resistance of staff and opposition to new changes that slow down the process of change in various areas.

Nurses can have a profound impact on the process of changes and proper management in hospitals. On the other hand, the nurses' lack of readiness to change and their dissatisfaction with the process can affect their mental status and even their performance, as well as the quality of provided care.

The initial reaction of individuals to changes is resistance due to different reasons. Studies on causes of resistance include issues such as attention and selective perception, habit, security issues, economic reasons, low motivation, psychological reasons, group and individual factors, lack of time to focus on change, lack of employees' participation in the values governing change, lack of explicit need, political reasons, lack of support, cultural and managerial barriers, supply and return, and lack of trust (Rezaei \& Haghani 2016).

The existence of resistance and negative attitude toward change in individuals tends to increase the timing of changes and its costs (Osumbah et al. 2015). Participation of individuals in the change projects can reduce the probability of resistance and accelerate the process of change (Koohi 2008). Thus, the level of readiness of individuals can be increased by determining the level of staff readiness and even make preparation by emphasizing on the strengths and resolving the weaknesses of the results of the surveys.

Change management and the employment of change management models are among the methods approved by experts in dealing with change. It is a systematic approach to deal with the transition or transformation of organization's goals, processes, or technologies. Change management aims to influence the change, control change, and help adapt to changes. Such strategies include adopting a structured approach to request change, as well as a mechanism to respond to requests and following them (Rouse 2018).

Boonstra (2008) makes managing change a means of keeping employees and organizations ready to learn and grow constantly. The change management allows for the effective implementation of the changes (Sadler 2002). Armenakis et al. (1993) define readiness as progressive cognition in the manifestations of resistance against or support for change. According to the results of the studies conducted by Afjeh and Abyaneh (2013), creating readiness among the people involved in the change, while influencing on their attitude, facilitates change. They also quoted Weber and Weber as claiming that recognizing individuals' attitudes plays a crucial role in successful and effective change.

One of the main aspects of organizational change efforts which influences the success or failure of these efforts is readiness for change among the members of the organization (Armenakis et al. 1993). Kameli et al. (2013), quoting Koklan, stated that admission of change means that there is a cooperation or desire to make a proposed change, which has many psychological and social reasons. Those who are dissatisfied with the status quo, the employees who are committed to the organization and customer's satisfaction is important to them, as well as employees who benefit from organizational changes welcome changes.

The current study, considering the importance of the results of the above-mentioned studies, aimed at examining the readiness of nurses, as the largest professional group in the health system to use the nursing orocess Kardex throug ADKAR model. The Adeccan model was presented by Priscilla in 2003 and includes five elements of awareness, desire, knowledge, ability, and reinforcement. The word ADKAR is an acronym of Awareness, Desire, Knowledge, Ability, and Reinforcement. Based on this model, readiness consists of five components, which by examining and paying attention to the factors affecting them, can identify the weaknesses and strengths of individuals in participating and implementing changes.

The Change Management Learning Center introduces the ADKAR model as follow: Awareness indicates the need for change, Desire stands for being interested in the company and supporting the idea of change, Knowledge means to have notion how to make change, Ability refers to the possibility of daily changes, and Reinforcement refers to how to make the change sustainable in the place (Prosci 2015).

Hiatt (2006) introduces ADKAR model as a tool to measure initial inclination and readiness in individuals and readiness to accept change in sense of gaining sufficient score in the components of this model and different dimensions of the adjective ADKAR model in a person or organization. Although people's resistance against change is a natural physiological and psychological response, human beings are adaptable and flexible creatures.

Once they are supported in different stages of change, they are surprisingly adapted to the changes in their surrounding. Self-change management requires insight into 
how to experience change in people and what they need for successful change. It is also necessary to gain insight into what helps individuals to make a successful transition (Karami 2018). ADKAR model is a people-centered evaluation model that measures individual readiness (Bedser 2012).

The results of the study by Brand (2013) showed that the ADKAR model was a simple ideal model to be used in hospitals and/or any other places that need change. Using ADKAR model is a good way to determine it, since it is the only model to measure individual readiness that can be used by the individuals themselves (Hiatt \& Creasey 2003). The current study aimed at examining the readiness of nurses in using nursing process Kardex based on ADKAR model.

\section{Materials and Methods}

In the current descriptive cross-sectional study investigated the efficiency of ADKAR model and the nurses' readiness to use nursing process Kardex. The study was conducted on 320 nurses working in hospitals affiliated to Iran University of Medical Sciences with a minimum of one-year work experience holding a bachelor's degree and/or higher in nursing. After obtaining the license and code of ethics from the Ethics Committee of the University, the subjects gave consent; they were assured that the study would had no harm and they could quit it if they had no more inclination to continue the study.

The subjects were selected using convenient sampling method proportional to the population size in each hospital. A demographic questionnaire and an ADKAR model questionnaire were employed to collect data. The demographic questionnaire included age, gender, work experience, type of hospital, and type of employment. The ADKAR model questionnaire consisted of 4 questions relevant to each of the components of Awareness, Desire, Knowledge, Ability, and Reinforcement, totally 20 questions, scored by Likert scale of 1-5, which a score of less than 3 in each area indicates individuals' lack of readiness in using a nursing process Kardex.

In the current study, the readiness means aquiring a score above 3 in all components of the ADKAR model pointed out by Hiatt (2006). According to the results of studies and the importance of using the nursing process in patient care, nursing manager of Iran University of Medical Sciences, along with the instructors of nursing, decided to add nursing diagnosis to nursing Kardex.

The researcher of the current study explained these changes to the nurses (the subjects) verbally before submitting the questionnaires to them. Content and face validity used to ensure the validity of the questionnaire. Cronbach's $\alpha$ was used to test the reliability of the instrument. The result of Cronbach's $\alpha$ in each component was 0.86 for awareness, 0.82 for desire, 0.87 for knowledge, 0.86 for ability, 0.86 for reinforcement, and 0.93 for total tool score.

The researcher visited the study centers during the week and after giving necessary explanations about the study and the ADKAR model, he submitted questionnaires and then gathered them at the end of the working shift. For data analysis, descriptive and inferential statistics were used. SPSS V. 16 was used to analyze data.

\section{Results}

Most of the participants in the study (95\%) were females. The mean age of the subjects was 31.86 years and the mean of their working experience was 8.21 years. Work experiences of 5-9 years and less than 5 years were the most frequent, indicating the rejuvenation of the nurses' community working in the hospitals. In terms of education, $90 \%$ of the nurses were at the undergraduate level and most of them were employed as a formal recruiter; $67.2 \%$ of nurses were working in university (educational) hospitals and $32.8 \%$ in general (medical) hospitals.

The mean and standard deviation of the nurses' responses to the components of ADKAR model questionnaire are shown in Table 1. The study results showed that more than half of nurses with a score over 3 in all components of ADKAR model had readiness to use nursing process Kardex (Tables 2). In examining the relationship between individual factors and nurses' readiness, the results showed that all components of the ADKAR model, except for reinforcement, were related to the type of hospital in the working place $(\mathrm{P}<0.001)$, also the mean scores were higher in university (educational) hospitals (Table 3 ).

\section{Discussion}

Being ready can lead people to a positive attitude towards changes. Positive attitude in the process of change can reduce the possible resistance against it, its implementation time, as well as the costs of change projects (Hiatt 2006).

According to the obtained results in each component of ADKAR model, and regarding gaining average score, which was above three in all of the components of the questionnaire, evidence showed that most nurses participating in the study were prepared to employ nursing process Kardex. Results of the study by Maleki et al. (2010) reflected that if structural empowerment constructs were 
Table 1. Mean $\pm S D$ of the nurses' responses to the components of ADKAR model questionnaire

\begin{tabular}{|c|c|c|}
\hline & Variable & Mean $\pm S D$ \\
\hline \multirow{5}{*}{ Awareness } & I understand the reasons for changing in the Nursing Process Kardex. & $3.21 \pm 1.31$ \\
\hline & I understand the difficulties in changing in the Nursing Process Kardex. & $19.3 \pm 1.17$ \\
\hline & & \\
\hline & I know how effective changing in the Nursing Process Kardex is. & $3.26 \pm 1.18$ \\
\hline & I am aware of the goals of the changing in the Nursing Process Kardex. & $3.22 \pm 1.17$ \\
\hline \multirow{5}{*}{ Desire } & To be part of these changes makes me feel excited. & $3.18 \pm 1.13$ \\
\hline & This change will provide me a lot of opportunities. & $0.1 \pm 1.11$ \\
\hline & & \\
\hline & I support the implementation of the change (using the Nursing Process Kardex). & $3.25 \pm 1.08$ \\
\hline & I benefit from the change (using the Nursing Process Kardex). & $3.05 \pm 1.06$ \\
\hline \multirow{5}{*}{ Knowledge } & I have the required skills to adapt to the changes. & $3.46 \pm 1.12$ \\
\hline & I understand how my work is related to change. & $3.35 \pm 1.15$ \\
\hline & & \\
\hline & Change is clear to me. & $3.21 \pm 1.13$ \\
\hline & I have the knowledge to adapt to the changes. & $3.41 \pm 1.09$ \\
\hline \multirow{5}{*}{ Ability } & I can adapt to change. & $3.43 \pm 1.05$ \\
\hline & I can positively help change. & $3.38 \pm 1.03$ \\
\hline & & \\
\hline & I can do better due to changes. & $3.39 \pm 1.04$ \\
\hline & I have the ability to do things at a level that is needed for the changes. & $3.33 \pm 1.08$ \\
\hline \multirow{5}{*}{ Reinforcement } & Our members of the group support this change. & $3.16 \pm 1.07$ \\
\hline & My manager supports this change. & $3.35 \pm 1.11$ \\
\hline & & \\
\hline & My uncertainty has been resolved. & $3.14 \pm 1.12$ \\
\hline & I personally develop with this change. & $3.17 \pm 1.08$ \\
\hline
\end{tabular}

implemented in the nurses' working places, it would increase their readiness for change. Therefore, it was recommended that planners and decision-makers should provide access to new knowledge and skills, and give the opportunity to employees to perform challenging tasks, and improve their readiness while empowering.

The results indicated the nurses' relative readiness and effectiveness of ADKAR model to assess their readiness; therefore, many nurses welcomed the employment of this model. Based on the results, the type of hospital and the employment status of nurses had a significant rela- tionship with their readiness therefore, readiness in educational hospitals with permanent and conscript nurses got higher scores. Hiatt (2006) stated that the ADKAR model was goal-oriented, a tool to help managers change their programs and guide their activities, a tool to guide managers and supervisors during the change, an assessment tool to identify ongoing changes, identification of potential weaknesses in changes, and a tool to plan the model of changes.

In this regard, the results of Hashemi's (2016) study showed that all components of readiness in ADKAR 
Table 2. Frequency distribution and numerical index of each of the components in nurses applying nursing process Kardex

\begin{tabular}{ccccc}
\hline \multirow{2}{*}{ Variables } & & Frequency & $\%$ & $\begin{array}{c}\text { Mean } \pm \text { SD } \\
\text { Maximum-Min }\end{array}$ \\
& No (1-2.9) & 105 & 32.8 & $22.3 \pm 1.01$ \\
Awareness & Yes (3-5) & 215 & 67.2 & $1-5$ \\
& No (1-2.9) & 118 & 36.9 & $3.12 \pm 0.88$ \\
Desire & Yes (3-5) & 202 & 63.1 & $1-5$ \\
Knowledge & No (1-2.9) & 82 & 25.6 & $336 \pm 0.89$ \\
& Yes (3-5) & 238 & 74.4 & $1-5$ \\
Ability & No (1-2.9) & 72 & 22.5 & $3.38 \pm 0.88$ \\
& Yes (3-5) & 248 & 77.5 & $1-5$ \\
Reinforcement & No (1-2.9) & 101 & 31.6 & $3.21 \pm 0.91$ \\
& Yes (3-5) & 219 & 68.4 & $1-5$ \\
\hline
\end{tabular}

Table 3. Demographic characteristics and numerical indices of each of the components in applying nursing process Kardex

\begin{tabular}{|c|c|c|c|c|c|c|}
\hline & & & Awa & & & \\
\hline imaiviau & 1 ractors & (\%) & Mean \pm SD & Test Results & Mean $\pm S D$ & Test Results \\
\hline Gender & Female & $304(95)$ & $3.23 \pm 1.02$ & $\begin{array}{c}P=0.474 \\
d f=318\end{array}$ & $3.12 \pm 0.89$ & $\begin{array}{l}t=0.061^{*} \\
P=0.951\end{array}$ \\
\hline & Male & $16(5)$ & $3.04 \pm 0.82$ & $t=0.718^{*}$ & $3.14 \pm 0.66$ & $\mathrm{df}=318$ \\
\hline & $20-29$ & 134(41.9) & $3.21 \pm 0.98$ & & $3.17 \pm 0.79$ & \\
\hline Age & $30-39$ & $147(45.9)$ & $3.23 \pm 1.01$ & $\begin{array}{l}P=0.985 \\
f=0.015^{* *}\end{array}$ & $3.09 \pm 0.94$ & $\begin{array}{l}P=0.695 \\
f=0.364^{* *}\end{array}$ \\
\hline & $40 \leq$ & $39(12.2)$ & $3.23 \pm 1.14$ & & $3.01 \pm 0.97$ & \\
\hline & $<5$ & $98(30.6)$ & $3.12 \pm 0.98$ & & $3.01 \pm 0.97$ & \\
\hline $\begin{array}{c}\text { Work } \\
\text { experience }\end{array}$ & $5-9$ & $107(33.4)$ & $3.25 \pm 0.99$ & $\mathrm{P}=0.711$ & $3.17 \pm 0.9$ & $P=0.597$ \\
\hline (years) & $10-14$ & $73(22.8)$ & $3.28 \pm 1.01$ & $f=0.459$ & $3 \pm 0.91$ & $f=0.628^{* x}$ \\
\hline & $15 \leq$ & $42(13.1)$ & $3.26 \pm 1.13$ & & $3.14 \pm 1.01$ & \\
\hline & BS & $288(90)$ & $3.21 \pm 1.01$ & $t=0.479^{*}$ & $3.11 \pm 0.9$ & $t=0.908^{*}$ \\
\hline Education & MS & 31(9.7) & $3.31 \pm 1$ & $P=0.632$ & $3.26+0.97$ & $P=0.365$ \\
\hline & $\mathrm{PhD}$ & $1(0.3)$ & - & $\mathrm{df}=31 /$ & $3.26 \pm 0.76$ & $d f^{-1},-2$ \\
\hline & Permanent & $137(42.8)$ & $3.29 \pm 1.08$ & & $3.06 \pm 0.97$ & \\
\hline & Temporary & $42(13.1)$ & $3.21 \pm 0.81$ & & $3.22 \pm 0.76$ & \\
\hline Employ- & & & & $\mathrm{f}=0.608^{* *}$ & & $\mathrm{f}=0.543^{* *}$ \\
\hline ment status & Contractual & $82(25.6)$ & $3.11 \pm 0.91$ & $P=0.611$ & $3.11 \pm 0.83$ & $P=0.653$ \\
\hline & Conscripts & $59(18.4)$ & $3.22 \pm 1.09$ & & $3.21 \pm 0.84$ & \\
\hline Type of & Educational & $215(67.2)$ & $3.39 \pm 0.95$ & $\mathrm{t}=4.448^{*}$ & $3.17 \pm 0.88$ & $t=1.428^{*}$ \\
\hline hospital & Medical & $105(32.8)$ & $2.87 \pm 1.04$ & $P<0.001$ & $3.02 \pm 0.88$ & $\mathrm{df}=318$ \\
\hline
\end{tabular}




\begin{tabular}{|c|c|c|c|c|c|}
\hline \multicolumn{2}{|c|}{ Individual Factors } & \multicolumn{2}{|c|}{ Knowledge } & \multicolumn{2}{|c|}{ Ability } \\
\hline & & Mean $\pm S D$ & Test Results & Mean \pm SD & Test Results \\
\hline \multirow{2}{*}{ Gender } & Female & $3.37 \pm 0.89$ & $\begin{array}{c}t=0.941^{*} \\
d f=318\end{array}$ & $3.04 \pm 0.9$ & $t=1.355^{*}$ \\
\hline & Male & $3.15 \pm 0.74$ & $P=0.348$ & $3.09 \pm 0.54$ & $P=0.176$ \\
\hline \multirow{3}{*}{ Age } & $20-29$ & $3.34 \pm 0.84$ & \multirow{3}{*}{$\begin{array}{c}P=0.55 \\
f=0.599^{* *}\end{array}$} & $3.39 \pm 0.82$ & \multirow{3}{*}{$\begin{array}{c}P=0.504 \\
f=0.687^{* *}\end{array}$} \\
\hline & $30-39$ & $3.33 \pm 0.9$ & & $3.34 \pm 0.91$ & \\
\hline & $40 \leq$ & $3.51 \pm 1.01$ & & $3.52 \pm 0.98$ & \\
\hline \multirow{4}{*}{ Work experience (years) } & $5<$ & $3.32 \pm 0.84$ & \multirow{4}{*}{$\begin{array}{c}P=0.154 \\
f=1.766^{* *}\end{array}$} & $3.42 \pm 0.81$ & \multirow{4}{*}{$\begin{array}{c}P=0.188 \\
f=1.604^{* *}\end{array}$} \\
\hline & $5-9$ & $3.31 \pm 0.88$ & & $3.26 \pm 0.92$ & \\
\hline & $10-14$ & $3.32 \pm 0.87$ & & $3.38 \pm 0.84$ & \\
\hline & $15 \leq$ & $3.65 \pm 1.02$ & & $3.61 \pm 0.99$ & \\
\hline \multirow{3}{*}{ Education } & BS & $3.37 \pm 0.89$ & \multirow{3}{*}{$\begin{array}{c}t=0.291^{*} \\
d f=317 \\
P=0.771\end{array}$} & $3.38 \pm 0.87$ & \multirow{3}{*}{$\begin{array}{c}t=0.016^{*} \\
d f=317 \\
P=0.987\end{array}$} \\
\hline & & & & & \\
\hline & MS & $3.32 \pm 0.83$ & & $3.39 \pm 0.98$ & \\
\hline \multirow{4}{*}{ Employment status } & Permanent & $3.44 \pm 0.99$ & \multirow{4}{*}{$\begin{array}{l}P=0.061 \\
f=2.481^{* *}\end{array}$} & $3.51 \pm 0.94$ & \multirow{4}{*}{$\begin{array}{c}P=0.01 \\
f=3.881^{* *}\end{array}$} \\
\hline & Temporary & $3.25 \pm 0.77$ & & $3.16 \pm 0.75$ & \\
\hline & Contractual & $3.16 \pm 0.8$ & & $3.54 \pm 0.85$ & \\
\hline & Conscripts & $3.51 \pm 0.81$ & & $3.54 \pm 0.85$ & \\
\hline \multirow{2}{*}{ Type of hospital } & Educational & $3.47 \pm 0.84$ & $\begin{array}{c}t=3.378^{*} \\
d f=318\end{array}$ & $0.84 \pm 0.86$ & \multirow{2}{*}{$\begin{array}{r}t=2.895^{*} \\
d f=318 \\
P=0.04\end{array}$} \\
\hline & Medical & $3.12 \pm 0.95$ & $P=0.001$ & $3.18 \pm 0.9$ & \\
\hline
\end{tabular}

\begin{tabular}{|c|c|c|c|c|}
\hline \multirow{2}{*}{\multicolumn{2}{|c|}{ Individual Factors }} & \multicolumn{3}{|c|}{ Reinforcement } \\
\hline & & \multicolumn{2}{|r|}{ Mean $\pm S D$} & Test Results \\
\hline \multirow{3}{*}{ Sex } & \multirow[t]{2}{*}{ Female } & \multicolumn{2}{|r|}{$3.22 \pm 0.91$} & $\mathrm{t}=1.498^{*}$ \\
\hline & & & \multirow[b]{2}{*}{$2.78 \pm 0.87$} & $\mathrm{df}=318$ \\
\hline & Male & & & $\mathrm{P}=0.135$ \\
\hline \multirow{3}{*}{ Age } & \multicolumn{2}{|l|}{$20-29$} & $3.17 \pm 0.92$ & \\
\hline & $30-39$ & & $3.19 \pm 0.86$ & $P=0.538$ \\
\hline & \multicolumn{2}{|l|}{$40 \leq$} & $3.35 \pm 1.06$ & \\
\hline \multirow{4}{*}{$\begin{array}{l}\text { Work experience } \\
\text { (years) }\end{array}$} & $<5$ & 3.17 & 0.93 & \multirow{4}{*}{$\begin{array}{l}P=0.274 \\
f=1.302^{* *}\end{array}$} \\
\hline & $5-9$ & 3.11 & 0.91 & \\
\hline & $10-14$ & 3.28 & 0.81 & \\
\hline & $15 \leq$ & 3.41 & 1.04 & \\
\hline \multirow{3}{*}{ Education } & \multirow[t]{2}{*}{ BSc. } & \multirow[t]{2}{*}{3.22} & \multirow[t]{2}{*}{0.93} & $t=0.436^{*}$ \\
\hline & & & & $d f=317$ \\
\hline & MSc. & 3.14 & 0.64 & $P=0.663$ \\
\hline
\end{tabular}




\begin{tabular}{|c|c|c|c|c|}
\hline \multirow{2}{*}{\multicolumn{2}{|c|}{ Individual Factors }} & \multicolumn{3}{|c|}{ Reinforcement } \\
\hline & & \multicolumn{2}{|c|}{ Mean $\pm S D$} & Test Results \\
\hline \multirow{4}{*}{ Employment status } & Permanent & 3.33 & 0.91 & \multirow{4}{*}{$\begin{array}{c}P=0.001 \\
f=5.451^{* *}\end{array}$} \\
\hline & Temporary & 2.94 & 0.86 & \\
\hline & Contractual & 2.96 & 0.84 & \\
\hline & Conscripts & 3.43 & 0.95 & \\
\hline \multirow{3}{*}{ Type of hospital } & Educational & 3.31 & 0.89 & $\mathrm{t}=3.048^{*}$ \\
\hline & & & & $d f=318$ \\
\hline & Medical & 2.98 & 0.92 & $P=0.002$ \\
\hline
\end{tabular}

model had direct relationship with establishing a physiological childbirth as a change executed in a hospital and can accelerate its process. While Bedser (2012) believed that effective factors in readiness in the ADKAR model can not be evaluated as effective independent factors, in the current study, five factors were interchanged into three factors: full readiness, realization of opportunity, and uncertainty, and the results indicated an overall readiness of employees of Eskom Company.

The study by Ghalandari \& Beigi (2014) showed that the ADKAR model had a positive impact on the change of Iran Khodro's software infrastructure to increase domestic and foreign sales rates. However, not all of ADKAR model factors had the same effect on change management in the company; awareness had the highest and knowledge the lowest effects.

Brand (2013) introduced ADKAR model as a simple and ideal model for people working in hospitals or any other places that need to change. He also recommended that the reasons for change should be clearly identified, managers pay more attention to the change proposals, and ambiguities of the change should be identified and then resolved at the proper moment.

Budiwati and Langi (2013), using a model called Elearning Maturity Model (EMM) designed based on ADKAR model, measured the readiness of elementary school teachers at Cinta Mekar and MI Al Huda in West Java to develop e-learning in the schools of the city. The results indicated that the education system was ready; however, there was a lack of training and supervision in e-learning. The researcher, then, stated that to solve these problems, ADKAR model-based activities such as the development, documentation, research, and revision groups should be defined.
In a qualitative case study, Lowery (2010) examined the impact of using ADKAR model in change management in the scientific databases of the Regis University in Colorado and using these data by faculty members and students. It was concluded that the researcher's lack of knowledge, that is a key factor in ADKAR model, confined his ability to provide effective progress in his change management responsibility. The researcher stated that according to the results of his study and based on the characteristics of the ADKAR model, he was confident that this model would lead to change management at the Regis University.

Kenny (2016) examined the experiences of the US vice presidents and their readiness to change the student affairs in small and private colleges of art schools in the United States and commented on their views towards readiness for change, communication, value of relationships, development of knowledge, and leadership change. The results of the current study showed that all participants tended to improve their organization and advance their employees as strong leaders on campus and create a qualified experience for their students.

In another study, Perez (2015) examined the experiences of nurses in readiness for a change in implementation of an electronic medical record. The results of the current study indicated that nurses understand and accept the change process and the lack of coordination and collaboration in the office environment. Also, the results advocated the survey on readiness to change at nursing environment during the implementation of the electronic system, and reinforce the argument that hospitals must make sure about the readiness of the staff.

In another study, trusting in God in life, the desire to acquire science and knowledge, planning, and trusting their own abilities had a significant relationship with the readi- 
ness of the staff to change. Personal readiness of employees for change should be considered by the executors as one of the most important factors influencing their reaction toward change, acceptance, and supporting it (Vaezi et al. 2016). Bowers (2012) believes that the result of change projects alter if resistive behaviors are identified.

The current study aimed at evaluating the nurses' readiness to use nursing process Kardex applying ADKAR model and its efficiency. The obtained results showed that more than half of the nurses attained enough readiness to use the nursing process Kardex based on ADKAR model. In addition, the average readiness score in educational hospitals was higher than that of non-educational hospitals. The current study results were in line with other studies conducted using ADKAR model. Using this model to assess nurses' readiness is a convenient and easy method for managers. In addition to measuring individual readiness, ADKAR model can also be influential to identify the weaknesses and strengths of an organization.

\section{Ethical Considerations}

\section{Compliance with ethical guidelines}

The present study was registered in November 2018, under the ethics code of IR.IUMS.FMD.REC1396.9311686002 received in the Ethics Committee of Iran University of Medical Sciences. Each subject signed a consent form and was assured that the study would have no harm and that they could quit the study if they had no more inclination to continue joining the study.

\section{Funding}

This project was supported by the Vice-Chancellor of Education of Iran University of Medical Sciences.

\section{Authors' contributions}

All authors contributed in designing, running, and writing all parts of the research.

\section{Conflict of interest}

The authors declared no conflict of interest

\section{Acknowledgments}

The authors wish to thank Iran University for its financial support and all nursing managers and nurses participating in the study.

\section{References}

Afjeh, S. \& Abysneh, N. 2013. The relationship between organizational learning and employee readiness for change in insurance companies. Journal of Management Studies, 23, 231-47.

Armenakis, A. A., Harris, S. G. \& Mossholder, K.W., 1993. Creating readiness for organizational change. Human Relations, 46(6), pp. 681-703. [DOI:10.1177/001872679304600601]

Bakhshi, N., 2011. Organizational change. Work and Society Monthly, 139, 60-7.

Bedser, M. B., 2012. An assesment of change readiness prior to significant organisational change [MSc. thesis]. Grahamstown: Rhodes University.

Boonstra, J., 2008. Dynamics of organizational change and learning Hoboken: John Wiley \& Sons Ltd.

Bowers, B., 2011. Managing change by empowering staff. Nurs ing Times, 107(32-33), pp. 19-21.

Brand, C. G. M., 2013. Factors influencing change management in a selected hospital in Saudi Arabia [MA. thesis]. Stellenbosch: Stellenbosch University.

Budiwati, S. D. \& Langi, A. Z., 2013. E-learning activity based on EMM and ADKAR change management for elementary schools. Information Systems International Conference (ISICO), 2013, pp. 255-60.

Carnall, C. A. 2002. Managing change [A. Alavi Persian trans.] Tehran: Governmental Management Training Center.

Farahani, Z. B., et al., 2016. The impact of training on nursing process implementation skills of surgical ward nurses. International Journal of Medical Research $\mathcal{E}$ Health Sciences, 5(7), pp. 268-72.

Ghalandari, P. G. \& Beigi, Z. M. 2014. The impact of implementing ADKAR model on OCM (Organizational Change Management) and foreign \& domestic sale rates of Iran Khodro Company. Journal of Social Issues \& Humanities, 2(8), pp. 208-20.

Hagos, F., et al., 2014. Application of nursing process and its affecting factors among nurses working in Mekelle zone hospitals, Northern Ethiopia. Nursing Research and Practice, 2014(675212), pp. 1-8. [DOI:10.1155/2014/675212]

Halkos, G., 2012. Importance and influence of organizational changes on companies and their employees [MA. thesis]. Volos, Greece: University of Thessaly.

Hashemi, M. 2016. [The relationship between organizational learning and readiness for change in promoting physiological delivery in hospitals under the methodology of Iran University of Medical Sciences (Persian)] [MSc. thesis]. Tehran: Iran University of Medical Sciences.

Hiatt, J. \& Creasey, T. J., 2003. Change management: The people side of change. Dulles: Prosci Learning Center.

Hiatt, J. 2006. ADKAR: A model for change in business, government, and our community. Dulles: Prosci Learning Center.

Kameli, M. J., et al. 2013. Review employee behavioral patterns versus change. Journal of Management Studies, 23, 103-34. 
Karami, S. 2016. [Change management: Organizations do not change, but people are changing (Persian)]. Electronic Journal of Knowledge Management Studies, 27.

Kenny, K. E. M., 2016. Change readiness: Realities and perceptions of vice presidents for student affairs at small, private liberal arts colleges [PhD. dissertation]. Fort Collins, Colorado: Colorado State University.

Koohi, S., 2008. [Change management and transformation (Persian)]. Tehran: Management Center of Statistics and Information Technology.

Lowery, M. S., 2010. Change management in a dynamic information technology environment: Inquiries into the ADKAR model for change management results [MSc. thesis]. Denver, Colorado: Regis University.

Maleki, M. R., Gohari, M. R. \& Ghorbanian, A., 2012. Relationship between structural empowering and nurses' readiness for change. Iran Journal of Nursing, 25(76), pp. 10-8.

Matbouei, M., Mohammadi, E. \& Zargarzadeh, M., 2015. [Assessment of barriers for recording nursing diagnoses (Persian)]. Advances in Nursing \& Midwifery, 24(84), pp. 27-34. [DOI:10.22037/anm.v24i84.7320]

Osumbah, B., Okwara, M. \& Onyango, M. 2015. Towards an engendered change management model. Linguistics, Culture $\mathcal{E}$ Education, 2015, Article ID 1.

Oxford English dictionary., 2018. Meaning of "Change" in the English dictionary [Internet]. Viewed 12 April 2018, https:// dictionary.cambridge.org/dictionary/english/change

Perez, A., 2015. Healthcare staff readiness for change based on EHR implementation: An exploratory qualitative inquiry [PhD. dissertation]. Minneapolis, Minnesota: Capella University.

Prosci., 2015. ADKAR model [Internet]. Change management learning center. Viewed 10 August 2015, http:/ / www.change-management.com/ecmlab/ecmlab-ikea.htm

Rezaei, H. \& Haghani, F., 2016. The causes of resistance to change and solutions to overcome It: A review of literature. Iranian Journal of Medical Education, 16, pp. 440-53.

Rouse, M. 2018. Change management [Internet]. Viewed 6 April 2018, https://searchcio.techtarget.com/definition/changemanagement

Sadler, Ph. 2002. Change management [Gh. R. Esmaeili Persian trans.], Tehran: Mir.

Senge, P. 2006. Dance of change [H. Akbari. \& M. Soltani Persian trans.], Tehran: ASIA Publications for Ariana Industrial Group.

Vaezi, R., Adnan Rad, A. \& Shahmohammadi, M., 2016. [An attitude to the change in the perspective of Islamic teachings and its constraints on the excitement of employees to change (Persian)]. Journal of Organizational Behavior Studies Quarterly, 3(1-2), pp. $1-30$ 